\title{
QUANTIFICAÇÃO DE CLOROFILAS EM FOLHAS DE MACIEIRAS 'ROYAL GALA' E 'FUJI' COM MÉTODOS ÓPTICOS NÃO-DESTRUTIVOS'
}

\author{
CASSANDRO VIDAL TALAMINI DO AMARANTE², CRISTIANO ANDRÉ STEFFENS ${ }^{3}$ \\ ODIMAR ZANUZO ZANARDI ${ }^{4}$, ERLANIDE OLIVEIRAALVES 5
}

RESUMO - O método-padrão para a quantificação de clorofilas em folhas é destrutivo e relativamente demorado. Com o advento dos medidores portáteis, a quantificação de clorofilas tornou-se fácil e rápida, podendo ser realizada de forma não-destrutiva a campo. Colorímetros também podem ser utilizados para a avaliação não-destrutiva da coloração de tecidos vegetais, e, portanto, para a quantificação de clorofilas em folhas. Este trabalho foi conduzido visando a avaliar a viabilidade de utilização de um colorímetro, como alternativa à utilização do medidor portátil de clorofila, para a quantificação não-destrutiva de clorofilas em folhas de macieiras 'Royal Gala' e 'Fuji'. Folhas de ambas as cultivares, com tonalidades variando de verde- amarelada (folha clorótica) a verde-escura, foram avaliadas individualmente, com um medidor de clorofila (Minolta SPAD-502) e um colorímetro (Minolta CR-400, no espaço de cores $L$, $C$ e $h^{o}$ ), seguido de quantificações destrutivas de clorofilas $a, b$ e totais. Os valores das leituras do medidor de clorofila e da relação $h^{\circ} /(L x C)$ do colorímetro aumentaram com o incremento nos teores de clorofilas nas folhas em macieiras 'Royal Gala' e 'Fuji'. Os modelos ajustados entre os teores de clorofilas e as leituras do medidor de clorofila e da relação $h^{\circ} /(L x C)$ do colorímetro apresentaram valores similares de $\mathrm{R}^{2}$, em ambas as cultivares. Os resultados obtidos demonstram que o colorímetro é uma alternativa viável na avaliação não-destrutiva do teor de clorofilas $\left(\mu \mathrm{g} . \mathrm{cm}^{-2}\right.$ de folha) em macieiras, especialmente de clorofilas $a$ e totais. Para tanto, os valores da relação $h^{\circ} /(L x C)$ do colorímetro devem ser previamente calibrados com a extração de clorofilas das folhas da cultivar de interesse.

Termos para indexação: Malus domestica Borkh, cor da folha, propriedades ópticas da folha, absorbância, refletância.

\section{QUANTIFICATION OF CHLOROPHYLLS IN LEAVES OF 'ROYAL GALA'AND 'FUJI'APPLE TREES WITH NON-DESTRUCTIVE OPTICAL METHODS}

\begin{abstract}
The standard method for chlorophylls quantification in leaves is destructive and time consuming. With the development of portable equipments, chlorophylls quantification became easy, quick, and affordable for non-destructive assessment at the field. Chroma meters can also be used to assess non-destructively plant tissues color and, therefore, to quantify chlorophylls in leaves. This work was carried out to evaluate the viability of using a chroma meter as an alternative to the leaf chlorophyll meter for nondestructive quantification of chlorophylls in the leaves of 'Royal Gala' and 'Fuji' apple trees. Leaves of both cultivars, with colors ranging from yellow-green (chlorotic) to dark green, were individually assessed with the chlorophyll meter (SPAD-502) and the chroma meter (Minolta CR-400, at the $L, C$, and $h^{\circ}$ color space), and, thereafter, destructively assessed for total chlorophyll and chlorophylls $a$ and $b$. The chlorophyll meter reading and the $h^{o} /(\operatorname{Lx} C)$ ratio for the chroma meter increased with the increment of chlorophylls content in the leaves of 'Royal Gala' and 'Fuji' apple trees. The adjusted models between chlorophylls content versus chlorophyll meter readings and the $h^{o} /(\operatorname{Lx} C)$ ratio for the chroma meter had similar $\mathrm{R}^{2}$ in both cultivars. The results show that the chroma meter is a viable alternative for non-destructive assessment of chlorophylls $\left(\mu \mathrm{g} . \mathrm{cm}^{-2}\right)$ in apple trees, especially of chlorophyll $a$ and total chlorophyll. For that purpose, it requires the calibration between the $h^{\circ} /(\mathrm{Lx} C)$ ratio of the chroma meter and the chlorophylls extracted from leaves of concerned cultivar.
\end{abstract}

Index terms: Malus domestica Borkh, leaf color, leaf optical properties, absorbance, reflectance.

${ }^{1}$ (Trabalho 224-07).Recebido em: 25-09-2007. Aceito para publicação em: 28-03-2008.

${ }^{2}$ Ph.D., Bolsista de Produtividade em Pesquisa do CNPq, Professor do Departamento de Agronomia, Centro de Ciências Agroveterinárias (CAV), Universidade do Estado de Santa Catarina (UDESC), Av. Luiz de Camões, 2090, Caixa Postal 281, CEP 88520-000, Lages-SC. Autor para correspondência. E-mail: amarante@cav.udesc.br

${ }^{3}$ Dr., Professor do Departamento de Agronomia, CAV/UDESC, Lages-SC. E-mail: steffens@cav.udesc.br

${ }^{4}$ Acadêmico do Curso de Agronomia, Bolsistas de Iniciação Científica do CNPq, CAV/UDESC, Lages-SC. E-mail: odimarzanardi@yahoo.com.br

${ }^{5}$ Acadêmica do Curso de Mestrado em Produção Vegetal, Bolsista da CAPES, CAV/UDESC, Lages-SC. E-mail: erlanea@gmail.com 


\section{INTRODUÇÃO}

O teor de clorofilas nas folhas é influenciado por diversos fatores bióticos e abióticos, estando diretamente relacionado com o potencial de atividade fotossintética das plantas (Taiz \& Zeiger, 2002). Portanto, sua quantificação é relevante no estudo de práticas culturais e de manejo, visando a aumentar o potencial fotossintético e o rendimento das espécies frutíferas.

O método-padrão para a determinação de clorofilas em laboratório (Arnon, 1949), ainda que fácil, apresenta desvantagens, já que resulta na coleta destrutiva do material vegetal, e é relativamente demorado (requer tempo necessário para a extração, via maceração com acetona ou outro solvente, e posterior leitura em espectrofotômetro). Com o advento dos medidores portáteis, que utilizam princípios ópticos nãodestrutivos, baseados na absorbância e/ou refletância da luz pelas folhas, a determinação de clorofilas tornou-se fácil e rápida, podendo ser realizada diretamente a campo (Richardson et al., 2002).

O equipamento Minolta SPAD-502 tem sido utilizado na quantificação de clorofilas, caracterizando-se pela rapidez, simplicidade e, principalmente, por possibilitar uma avaliação não-destrutiva do tecido foliar. Para a quantificação de clorofilas, a folha é presa entre uma haste flexível e outra rígida, pressionando-se a haste flexível no momento da medição. A haste flexível emite luz, que atravessa o tecido foliar e atinge um receptor (fotodiodo de silicone) na haste rígida, que converte a luz transmitida em sinais elétricos analógicos. Por meio do conversor $\mathrm{A} / \mathrm{D}$, esses sinais são amplificados e convertidos em sinais digitais, sendo usados por um microprocessador para calcular a leitura SPAD ("Soil Plant Analytical Division Value"). A intensidade de cor verde na folha é detectada no aparelho através da quantidade de luz absorvida pela folha, nos comprimentos de onda $(\lambda)$ de $650 \mathrm{~nm}$ (vermelho) e $940 \mathrm{~nm}$ (vermelho distante próximo). A luz absorvida no $\lambda$ de $650 \mathrm{~nm}$ (pelas clorofilas, sem a interferência ocasionada pelos carotenóides) indica a quantidade de clorofilas, enquanto a quantidade absorvida próximo do $\lambda$ de $940 \mathrm{~nm}$ serve como referência interna na compensação da espessura e conteúdo de água da folha (Swiader \& Moore, 2002). A pequena área do sensor do equipamento $(2 \times 3 \mathrm{~mm})$ permite sua utilização para a quantificação de clorofilas mesmo em folhas de pequeno tamanho. Esse equipamento tem sido utilizado com sucesso para diagnosticar o estado nutricional de diversas espécies frutíferas, como macieira (Neilsen et al., 1995; Porro et al., 2001a), videira (Porro et al., 2001a e 2001b; Rupp et al., 1999; Rupp \& Trankle, 1995), pessegueiro (Thomidis \& Tsipouridis, 2005), pereira (Chang \& Chang, 1998; Peryea \& Kammereck, 1997), mangueira (Chang \& Chang, 1998), cítricas (Araújo et al., 2004; Esposti et al., 2003; Jifon et al., 2005; Li et al., 1998), lichieira (Chang \& Chang, 1998), meloeiro (Azia \& Stewart, 2001), entre outras. Todavia, como o equipamento fornece uma leitura em unidades arbitrárias (leitura SPAD de teores de clorofila, na faixa de 0 a 99,9), recomenda-se que o mesmo seja previamente calibrado com as extrações de clorofilas da cultura de interesse (Azia \& Stewart, 2001; Markwell et al., 1995; Uddling et al., 2007).

O colorímetro Minolta CR (séries 100; 200; 300 e 400) também pode ser utilizado para a avaliação não-destrutiva da coloração de tecidos vegetais, como ocorre em frutos (Amarante et al., 2007). Esse equipamento tem sensibilidade similar à do olho humano, com a vantagem de produzir a mesma leitura, independentemente da condição de iluminação do ambiente, já que utiliza uma fonte interna de luz e um sistema de compensação de leitura, constituído de dois sensores internos, um que mede a luz refletida da superfície do tecido vegetal e outro sensor que mede a luz da fonte de iluminação. A fonte de luz do equipamento gera radiação difusa (com diferentes ângulos de incidência), e o sensor interno recebe a luz refletida verticalmente pela superfície do tecido no espaço de cores $L, C$ e $h^{o}$ (McGuire, 1992). Esse sistema usa o mesmo diagrama do espaço de cores $L, a$ e $b$, porém com coordenadas cilíndricas ao invés de coordenadas retangulares. Os termos $L, C$ e $h^{o}$ indicam brilho ('lightness'), cromaticidade e ângulo hue, respectivamente. Os valores de $h^{o}$ apresentam as seguintes correspondências quanto às cores da superfície do tecido vegetal: $0^{\circ} /$ vermelho, $90^{\circ} /$ amarelo, $180^{\circ} /$ verde e $270^{\circ}$ /azul. Portanto, o valor de $h^{o}$ do equipamento permite quantificar o teor de clorofilas em folhas (folha verde intensa, com elevado teor de clorofila, apresentando $h^{\circ}$ próximo de $180^{\circ}$, e folha clorótica, com baixo teor de clorofila, apresentando $h^{\circ}$ próximo de $90^{\circ}$ ). Em adição ao $h^{\circ}$, os valores de $L$ permitem detectar tonalidades de verde (valores baixos correspondem à coloração verde-escura e valores altos à coloração verde-clara), enquanto os valores de $C$ identificam a pureza da cor (valores altos indicam maior desvio a partir do ponto correspondente ao cinza, de menor $C)$. Todavia, esse equipamento nunca foi avaliado quanto à viabilidade de utilização na quantificação de clorofila em folhas, através da medição dos atributos de cor.

Este trabalho foi conduzido visando a avaliar a viabilidade de utilização do colorímetro, como alternativa ao emprego do medidor de clorofila SPAD-502, para a quantificação nãodestrutiva dos teores de clorofilas em folhas de macieiras 'Royal Gala' e 'Fuji'.

\section{MATERIAL E MÉTODOS}

Foram coletadas 20 folhas de macieiras 'Royal Gala' e 'Fuji' (com 12 anos de idade, sobre porta-enxerto M.9, cultivadas em pomar comercial no município de Lages-SC), em pleno desenvolvimento vegetativo (janeiro/2007), cujas tonalidades variavam de verde-amarelada (clorótica) a verde-escura. Em seis pontos de cada folha, foram feitas leituras utilizando o medidor portátil de clorofila SPAD-502 e o colorímetro CR-400 (ambos da Konica Minolta ${ }^{\circledR}$, Japão), procedendo-se o cálculo da média das leituras por folha. O colorímetro CR-400 foi utilizado com ponteira de vidro côncava CR-A33f (abertura de $8 \mathrm{~mm}$ ) para a quantificação da cor no espaço de cores $L, C$ e $h^{\circ}$ (McGuire, 1992), sendo as folhas colocadas sobre superfície branca (folha de papel branco) para evitar qualquer interferência da cor dessa superfície nas leituras de refletância da folha.

Em cada folha, nos mesmos pontos onde foram feitas as leituras de cor com o SPAD-502 e o colorímetro CR-400, com o auxílio de um furador de rolha, foram removidos discos $(\varnothing=1,6 \mathrm{~cm})$, nos quais foram determinadas a massa fresca (com uma balança 
analítica, com precisão de $0,0001 \mathrm{~g}$ ) e a área total (com um integrador de área foliar LI-COR modelo LI-3050A). Os discos (seis) de cada folha foram imediatamente macerados em acetona a $80 \%$, na presença de $\mathrm{CaCO}_{3}$, em ambiente com fonte de iluminação artificial verde de baixa intensidade. Foi utilizada a proporção de $0,225 \mathrm{~g}$ de massa fresca de tecido foliar para $50 \mathrm{~mL}$ de acetona $80 \%$. Os extratos obtidos foram filtrados através de papel-filtro rápido e coletados em balões volumétricos de $25 \mathrm{~mL}$, completando-se o volume ao final da filtragem. A densidade ótica dos filtrados foi lida em espectrofotômetro (Carl Zeizz ${ }^{\circledast}, \mathrm{UV}-\mathrm{Vis}$ Spekol, Alemanha) nos $\lambda$ de 645 e 663 nm, utilizando cubetas de quartzo. A partir dessas leituras, determinou-se a concentração $\left(\mathrm{mg} . \mathrm{cm}^{-3}\right)$ de clorofilas $a, b$ e totais nas soluções de leitura, por meio de fórmulas propostas por Arnon (1949):

Clorofila $a$

Clorofila $b$

Clorofilas totais

$$
\begin{aligned}
& =\left(12,7 \times \mathrm{A}_{663 \mathrm{~nm}}\right)-\left(2,69 \times \mathrm{A}_{645 \mathrm{~nm}}\right) \\
& =\left(22,9 \times \mathrm{A}_{645 \mathrm{~nm}}\right)-\left(4,68 \times \mathrm{A}_{663 \mathrm{~nm}}\right) \\
& =\left(20,2 \times \mathrm{A}_{645 \mathrm{~nm}}\right)+\left(8,02 \times \mathrm{A}_{663 \mathrm{~nm}}\right)
\end{aligned}
$$

Esses valores foram transformados para teores de clorofilas $a, b$ e totais nas folhas, expressos em unidades de área $\left(\mu \mathrm{g} . \mathrm{cm}^{-2}\right)$ e de massa fresca $\left(\mu \mathrm{g} . \mathrm{g}^{-1}\right)$, segundo sugestão de Richardson et al. (2002).

Foram feitas análises de regressão linear e não-linear entre as leituras obtidas com o auxílio dos dois equipamentos e os teores de clorofilas $a, b$ e totais quantificados nas folhas, utilizando o programa SAS.

\section{RESULTADOS E DISCUSSÃO}

Os valores de leitura do SPAD-502 apresentaram aumento linear em macieiras 'Royal Gala' (Figura 1) e 'Fuji' (Figura 2), com $\mathrm{o}$ incremento nos teores de clorofilas $a, b$ e totais nas folhas.

Houve uma relação linear entre valores individuais de $h^{\circ}$, $L$ e $C$, quantificados com o colorímetro CR-400 e os teores de clorofilas $a, b$ e totais, expressos em unidades de área $\left(\mu \mathrm{g} . \mathrm{cm}^{-2}\right.$ de folha) e de massa fresca $\left(\mu \mathrm{g} . \mathrm{g}^{-1}\right)$, em folhas de macieiras 'Royal Gala' e 'Fuji' (dados não-apresentados). Houve aumento do $h^{\circ}$ com o incremento nos conteúdos e concentrações de clorofilas $a, b$ e totais nas folhas de ambas as cultivares, indicando uma mudança de coloração de verde-amarela (folha clorótica) para verde-intensa. Os valores de $L$ e $C$ reduziram-se com o aumento nos teores de clorofilas $a, b$ e totais nas folhas de ambas as cultivares, indicando uma redução no brilho e na cromaticidade.

A utilização da relação $h^{o} /(L x C)$ resultou em melhor ajuste de modelos com os teores de clorofilas $a, b$ e totais nas folhas de macieiras 'Royal Gala' (Figura 1) e 'Fuji' (Figura 2), do que a utilização individual desses atributos de cor (dados nãoapresentados). Com o incremento nos teores de clorofilas $a, b \mathrm{e}$ totais nas folhas, houve um aumento da relação $h^{\circ} /(L x C)$, sendo esse aumento linear em 'Royal Gala' (Figura 1) e assintótico em 'Fuji' (Figura 2).

Os modelos ajustados entre os teores de clorofilas $a, b \mathrm{e}$ totais (expressos em unidades de área e de massa fresca) e os valores de leitura do SPAD-502 e da relação $h^{\circ} /(L \mathrm{x} C)$ do colorímetro Minolta CR-400 apresentaram valores similares de $\mathrm{R}^{2}$, em ambas as cultivares (Figuras 1 e 2).

Os modelos ajustados para os teores de clorofilas expressos em unidades de área apresentaram valores de $\mathrm{R}^{2}$ similares ou ligeiramente superiores em relação àqueles ajustados para teores de clorofilas expressos em unidades de massa fresca, referente às clorofilas $a, b$ e totais, tanto para a leitura SPAD como para o valor da relação $h^{\circ} /(L x C)$ do colorímetro CR-400, em ambas as cultivares (Figuras 1 e 2). Portanto, a variação que ocorre na área foliar específica $\left(\mathrm{cm}^{2} \cdot \mathrm{g}^{-1}\right.$ de massa fresca), influenciada por diferenças entre folhas na espessura do mesófilo e conteúdo de água, resulta em maior variabilidade nos teores de clorofilas expressos em unidades de massa fresca $\left(\mu \mathrm{g} \cdot \mathrm{g}^{-1} \mathrm{de}\right.$ massa fresca). Portanto, a expressão dos teores de clorofilas em unidades de área $\left(\mu \mathrm{g} . \mathrm{cm}^{-2}\right)$ deve ser preferida, quando estimada com a utilização do SPAD-502 e do colorímetro CR-400, já que resulta em menor erro.

Os modelos ajustados de leitura SPAD e da relação $h^{\circ} /$ $(L x C)$ do colorímetro CR-400 apresentaram maior $\mathrm{R}^{2}$ para a estimativa dos teores de clorofilas $a$ e totais do que para a clorofila $b$, tanto em 'Royal Gala' (Figura 1) como em 'Fuji' (Figura 2). Resultados similares foram reportados por Richardson et al. (2002), trabalhando com o SPAD-502 e índices de refletância espectral em folhas de bétula (Betula papyrifera Marsh.), demonstrando que a utilização de métodos não destrutivos ópticos são melhores para a estimativa dos conteúdos e concentrações de clorofilas $a$ e totais do que de clorofila $b$.

Neves et al. (2005), trabalhando com o SPAD-502 em algodoeiro, também observaram maior correlação das leituras do equipamento com os teores de clorofila $a$ comparativamente a clorofila $b$. Segundo esses autores, isto ocorre tendo em vista que o pico de absorção na faixa vermelha do espectro pela clorofila $a(663 \mathrm{~nm})$, além de ser maior que o da clorofila $b$, está muito próximo do comprimento de onda emitido pelo SPAD-502 (650 $\mathrm{nm})$. Com isso, a maior parte da luz vermelha, emitida pelo aparelho, é absorvida pela clorofila $a$. Portanto, em estudos que visam à calibração desse aparelho, para se obterem medidas indiretas de clorofila, devem ser evitadas leituras em folhas sombreadas, pois, nelas, o teor de clorofila $b$ é proporcionalmente maior do que o de clorofila $a$, quando comparadas com as folhas em pleno sol (Taiz \& Zeiger, 2002).

Como a função das clorofilas é absorver quantidades de luz incidente, poder-se-ia supor que a medição da quantidade de radiação absorvida pela folha com o SPAD-502 resultaria em melhor estimativa de clorofilas do que a medição da luz refletida pela superfície da folha, obtida com o colorímetro Minolta CR400. Todavia, os resultados obtidos mostram que o colorímetro Minolta CR-400 apresenta resultados similares ao SPAD-502, para a quantificação de clorofilas em folhas de macieiras.

O SPAD-502, mesmo com sistema de compensação para alterações na espessura e conteúdo de água da folha (luz absorvida no $\lambda$ de $940 \mathrm{~nm}$ ), apresenta grandes variações de leitura entre espécies (Chang \& Chang 1998; Richardson et al., 2002) e entre genótipos (Jifon et al., 2005; Neilsen et al., 1995; Rupp et al., 1999; Rupp \& Trankle, 1995) de plantas frutíferas, cultivados em uma mesma condição de ambiente, devido a diferenças na 
estrutura e anatomia foliar. Folhas de um mesmo genótipo de videira ou de macieira podem apresentar grandes variações no índice SPAD, em função do estádio fenológico, posição/idade da folha na planta e ano de avaliação (Neilsen et al., 1995; Porro et al., 2001b; Rupp \& Trankle, 1995). Em Citrus sp, folhas de plantas crescidas a campo apresentaram maior espessura e, portanto, maiores valores de leitura SPAD comparativamente a plantas crescidas em estufa, para um mesmo teor foliar de clorofilas totais (Jifon et al., 2005). Mesmo folhas sombreadas de uma planta, apesar da menor espessura do mesófilo em relação a folhas a pleno sol, apresentam maiores valores de leituras SPAD502 , devido ao incremento na relação clorofilas $a / b$ (Hoel \& Solhaug, 1998; Martínez \& Guiamet, 2004). Limitações associadas a diferenças quanto à espessura/anatomia foliar, influenciadas por fatores da planta e ambientais, requerem a calibração do SPAD-502 com as extrações de clorofilas nas condições particulares de investigação.

Todavia, deve-se ressaltar que, para a quantificação de clorofilas em folhas com o auxílio do colorímetro, à semelhança do que ocorre com o SPAD-502, devem ser tomados cuidados quanto à idade/posição da folha, estádio fenológico e condições de cultivo de macieiras, procedendo-se a calibração da relação $h^{\circ} /(L \times C)$ do equipamento com as extrações de clorofilas da cultivar com que se está trabalhando.
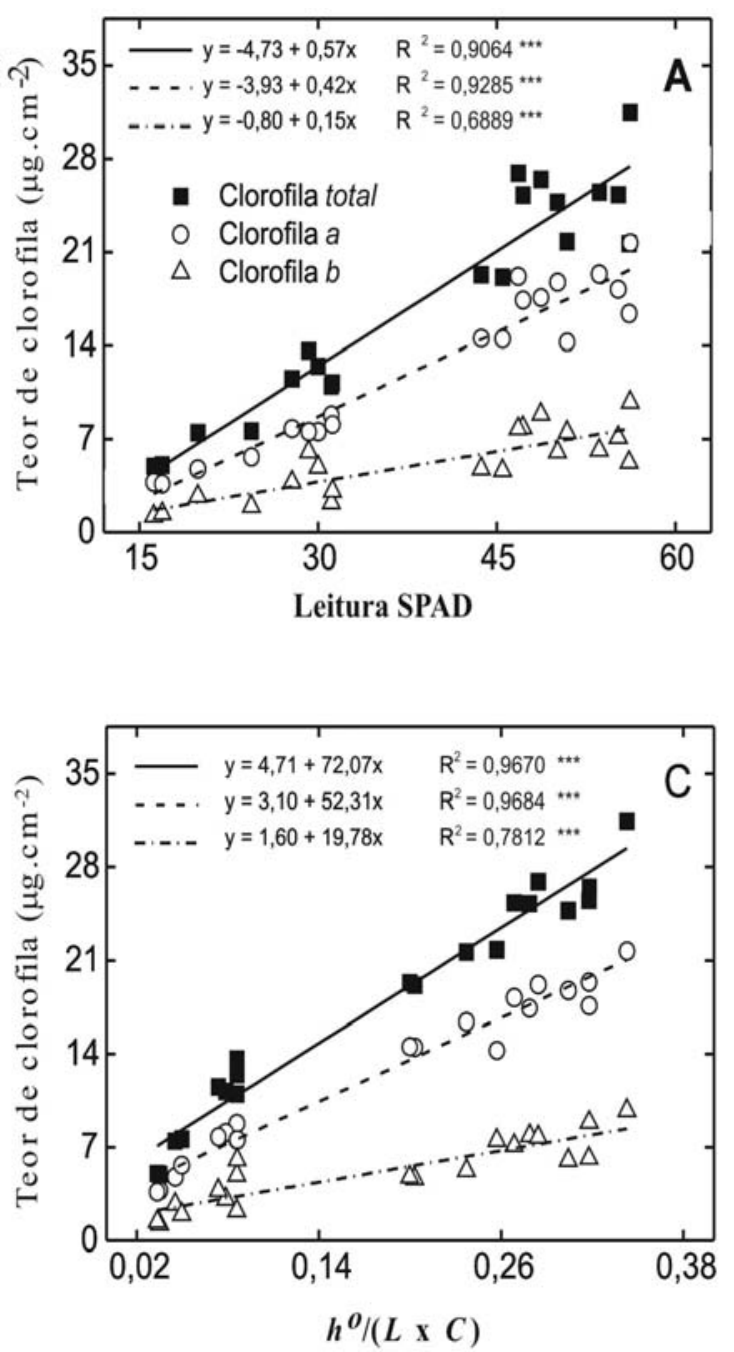
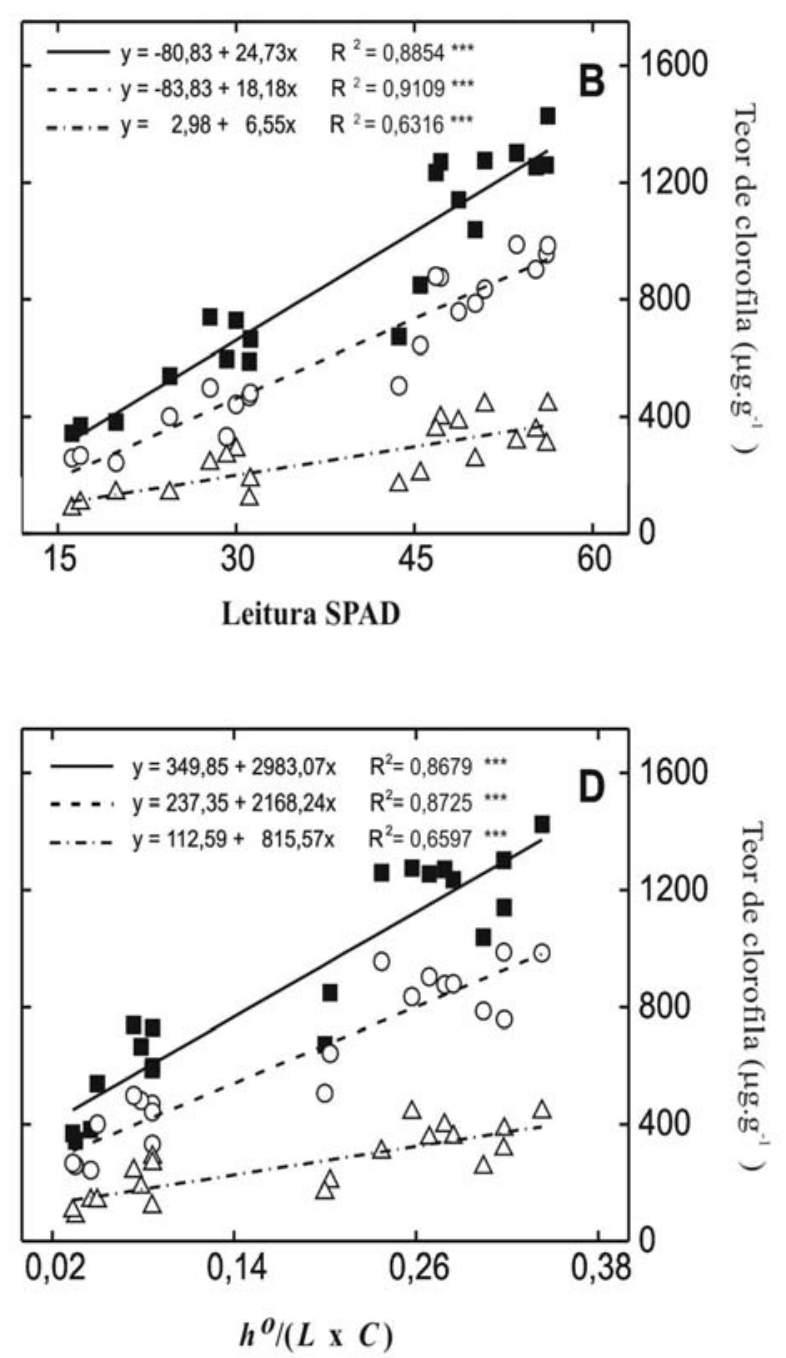

FIGURA 1 - Relação entre valores de leitura do SPAD-502 (A e B) e o atributo de cor $h^{\circ} /(L \mathrm{x} C)$ do colorímetro CR-400 (C e D) versus teores de clorofilas $a, b$ e totais, em unidades de área $\left(\mu \mathrm{g} . \mathrm{cm}^{-2}\right.$; gráficos à esquerda) e de massa fresca ( $\mu \mathrm{g} . \mathrm{g}^{-1}$; gráficos à direita), em folhas de macieiras 'Royal Gala'. 

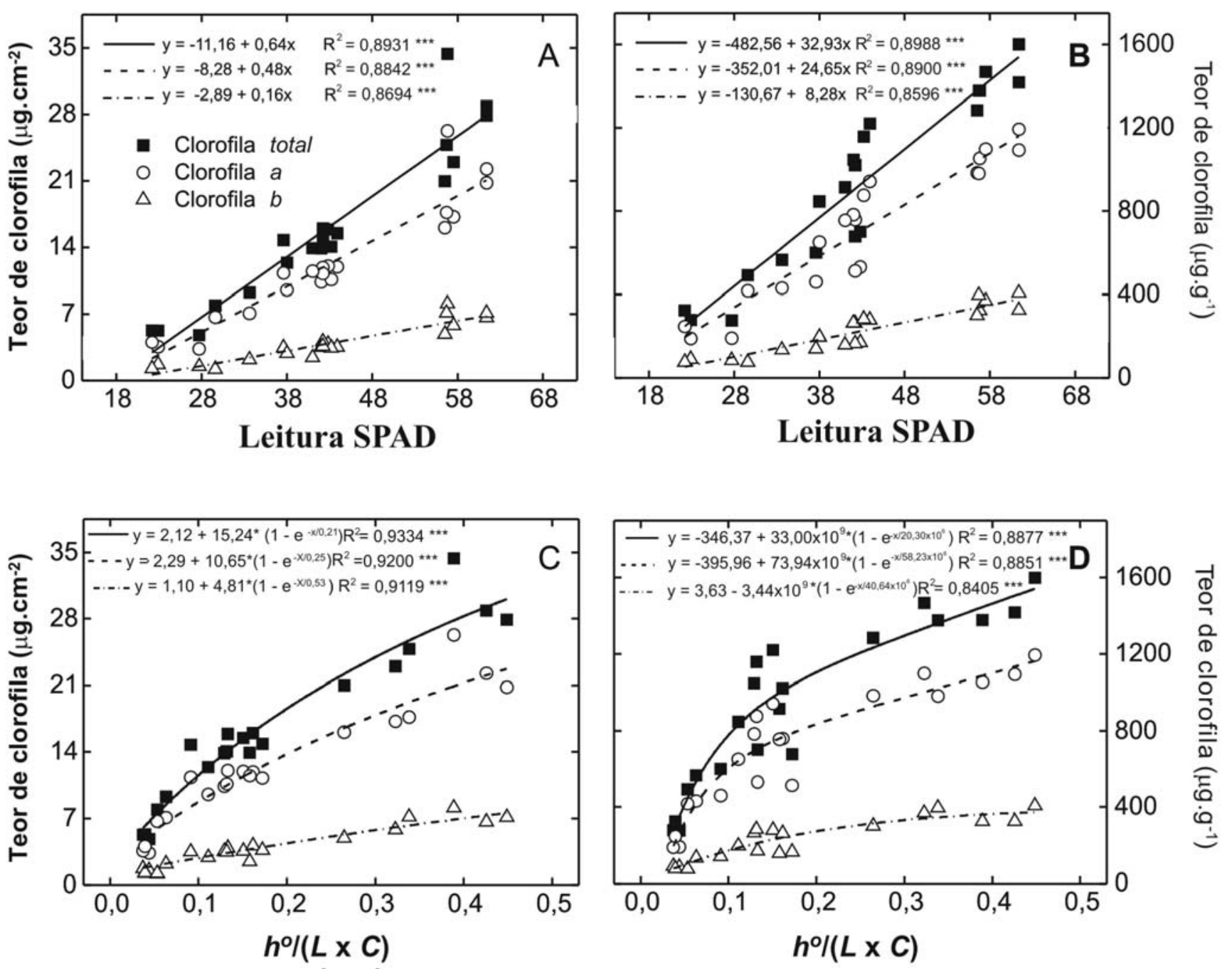

FIGURA 2- Relação entre valores de leitura do SPAD-502 (A e B) e o atributo de cor $h^{o} /(L \mathrm{x} C)$ do colorímetro CR-400 (C e D) versus teores de clorofilas $a, b$ e totais, em unidades de área $\left(\mu \mathrm{g} . \mathrm{cm}^{-2}\right.$; gráficos à esquerda) e de massa fresca ( $\mu \mathrm{g} . \mathrm{g}^{-1}$; gráficos à direita), em folhas de macieiras 'Fuji'.

\section{CONCLUSÃO}

Os resultados obtidos demonstram a viabilidade técnica de utilização do colorímetro (Minolta CR-400) na avaliação quantitativa e não-destrutiva dos teores de clorofilas $a, b$ e totais em folhas de macieiras 'Royal Gala' e 'Fuji', com o cálculo da relação $h^{o} /(L \mathrm{x} C)$. O colorímetro apresenta maior confiabilidade quando utilizado para a quantificação dos teores de clorofilas $a$ e totais, expressos em unidades de área $\left(\mu \mathrm{g} . \mathrm{cm}^{-2}\right.$ de folha).

\section{AGRADECIMENTOS}

Os autores agradecem ao Conselho Nacional de Desenvolvimento Científico e Tecnológico ( $\mathrm{CNPq})$, à Financiadora de Estudos e Projetos (FINEP) e à Coordenação de Aperfeiçoamento de Pessoal de Nível Superior (CAPES), pelo apoio financeiro a este projeto.

\section{REFERÊNCIAS}

AMARANTE, C.V.T. do; STEFFENS, C.A.; MOTA, C.S.; SANTOS, H.P. dos. Radiação, fotossíntese, rendimento e qualidade de frutos em macieiras 'Royal Gala' cobertas com telas antigranizo. Pesquisa Agropecuária Brasileira, Brasília, v.42, n.7, p. $925-931,2007$.

ARAÚJO, R.A. de; SIQUEIRA, D.L. de; MARTINEZ, C.A.; FERNANDES, A.R. Características biométricas, índice SPAD-502 e emissão da fluorescência em porta-enxertos de citros. Revista Ceres, Viçosa, v.51, n.294, p.189-199, 2004.

ARNON, D.I. Copper enzymes in isolated chloroplasts: polyphenoloxidases in Beta vulgaris. Plant Physiology, Maryland, v.24, p.1-15, 1949.

AZIA, F.; STEWART, K.A. Relationship between extractable chlorophyll and SPAD values in muskmelon leaves. Journal of 
Plant Nutrition, Abingdon, v.24, n.6, p.961-966, 2001.

CHANG, C.S.; CHANG, L.R. Two rapid determination methods for total chlorophyll content in fruit tree leaves. Bulletin of Taichung District Agricultural Improvement Station, Changhua, v.59, p.37-45, 1998.

ESPOSTI, M.D.D.; SIQUEIRA, D.L. de; PEREIRA, P.R.G.; VENEGAS, V.H.A.; SALOMÃO, L.C.C.; MACHADO FILHO, J.A. Assessment of nitrogenized nutrition of citrus rootstocks using chlorophyll concentrations in the leaf. Journal of Plant Nutrition, Abingdon, v.26, n.6, p.1287-1299, 2003.

HOEL, B.O.; SOLHAUG, K.A. Effect of irradiance on chlorophyll estimation with the Minolta SPAD-502 leaf chlorophyll meter. Annals of Botany, London, v.82, n.3, p.389-392, 1998.

JIFON, J.L.; SYVERTSEN, J.P.; WHALEY, E. Growth environment and leaf anatomy affect nondestructive estimates of chlorophyll and nitrogen in Citrus sp leaves. Journal of the American Society for Horticultural Science, Alexandria, v.130, n.2, p.152-158, 2005.

LI, Y.C.; ALVA, A.K.; CALVERT, D.V.; ZHANG, M. A rapid nondestructive technique to predict leaf nitrogen status of grapefruit tree with various nitrogen fertilization practices. HortTechnology, Alexandria, v.8, n.1, p.81-86, 1998.

MARKWELL, J.; OSTERMAN, J.C.; MITCHELL, J.L. Calibration of the Minolta SPAD-502 leaf chlorophyll meter. Photosynthesis Research, Amsterdam, v.46, n.3, p.467-472, 1995.

MARTÍNEZ, D.E.; GUIAMET, J.J. Distortion of the SPAD 502 chlorophyll meter readings by changes in irradiance and leaf water status. Agronomie, Les Ulis, v.24, n.1, p.41-46, 2004.

McGUIRE, R.G. Reporting of objective color measurements. HortScience, Alexandria, v. 27, n.12, p.1254-1255, 1992.

NEILSEN, D.; HOGUE, E.J.; NEILSEN, G.H.; PARCHOMCHUK, P. Using SPAD-502 values to assess the nitrogen status of apple trees. HortScience, Alexandria, v.30, n.3 p.508-512, 1995.

NEVES, O.S.C.; CARVALHO, J.G. de; MARTINS, F.A.D.; PÁDUA, T.R.P. de; PINHO, P.J. de. Uso do SPAD-502 na avaliação dos teores foliares de clorofila, nitrogênio, enxofre, ferro e manganês do algodoeiro herbáceo. Pesquisa Agropecuária Brasileira, Brasília, v.40, n.5, p.517-521, 2005.
PERYEA, F.J.; KAMMERECK, R. Use of Minolta SPAD-502 chlorophyll meter to quantify the effectiveness of mid-summer trunk injection of iron on chlorotic pear trees. Journal of Plant Nutrition, Abingdon, v.20, n.11, p.1457-1463, 1997.

PORRO, D.; DORIGATTI, C.; STEFANINI, M.; CESCHINI, A. Use of SPAD meter in diagnosis of nutritional status in apple and grapevine. Acta Horticulturae, Leven, n.564, p.243-252, 2001a.

PORRO, D.; BERTAMINI, M.; DORIGATTI, C.; STEFANINI, M.; CESCHINI, A. Lo SPAD nella diagnosi dello stato nutrizionale della vite. Informatore Agrario, Verona, v.57, n.26, p.49-55, 2001 b.

RICHARDSON,A.D.; DUIGAN, S.P.; BERLYN, G.P. An evaluation of noninvasive methods to estimate foliar chlorophyll content. New Phytologist, Lancaster, v.153, n.1, p.185-194, 2002.

RUPP, D.; TRANKLE, L. A non-destructive measurement method for chlorophyll in grapevines. Mitteilungen Klosterneuburg, Rebe und Wein, Obstbau und Fruechteverwertung, v.45, n.5/6, p.139-142, 1995 .

RUPP, D.; TRANKLE, L.; FOX, R. Non-destructive measurement of chlorophyll in grapes - evaluation of varietal influences and effects of sampling methods. Mitteilungen Klosterneuburg, Rebe und Wein, Obstbau und Fruechteverwertung, v.49, n.3, p.86-92, 1999.

SWIADER, J.M.; MOORE, A. SPAD-chlorophyll response to nitrogen fertilization and evaluation of nitrogen status in dryland and irrigated pumpkins. Journal of Plant Nutrition, Abingdon, v. 25, n.5, p.1089-1100, 2002.

TAIZ, L.; ZEIGER, E. Plant physiology. 3. ed. Sunderland: Sinauer Associates, 2002. 690p.

THOMIDIS, T.; TSIPOURIDIS, C. Influence of rootstocks, $\mathrm{pH}$, iron supply (in nutrient solutions) and Agrobacterium radiobacter on chlorophyll and iron concentration in leaves of a peach variety. Journal of Plant Nutrition, Abingdon, v.28, n.10, p.1833-1842, 2005.

UDDLING, J.; GELANG-ALFREDSSON, J.; PIIKKI, K.; PLEIJEL, $\mathrm{H}$. Evaluating the relationship between leaf chlorophyll concentration and SPAD-502 chlorophyll meter readings. Journal Photosynthesis Research, Dordrecht, v.91, n.1, p.37-46, 2007. 